\title{
Literatura e identidad. Experiencias de lectura literaria en la infan- cia y adolescencia de cinco escritores españoles contemporáneos'
}

Literature and Identity: Experiences Reading Literature in the Childhood and Adolescence of Five Contemporary Spanish Writers

\author{
MARTA SANJUÁN ÁLVAREZ \\ JUAN SENÍS FERNÁNDEZ \\ Universidad de Zaragoza \\ Grupo de investigación ELLIJ \\ España \\ msanjalv@unizar.es \\ jsenis@unizar.es
} (Recibido: 22-O3-2OI6;
aceptado: 2O-I2-2OI6)

Resumen. El propósito de este trabajo es reflexionar sobre la educación literaria desde la perspectiva de la relación entre literatura y vida. En estos momentos de crisis de las humanidades, creemos necesario reivindicar de nuevo el insustituible papel de la literatura en la formación de los niños y adolescentes. Para valorar el poder transformador de la literatura y las dimensiones vitales de la experiencia de la lectura literaria en los estadios tempranos de la construcción de la identidad, se exploran cinco textos autobiográficos de cinco escritores españoles contemporáneos como fuente de información introspectiva y retrospectiva, en una línea de investigación etnográfica. En estos lectores las excepcionales experiencias lectoras vividas se suman a una capacidad expresiva igualmente excepcional para comunicar lo que esa relación intensa con la literatura ha representado en su trayectoria vital y en su construcción como sujetos.

Palabras clave: literatura e identidad; educación literaria; literatura contemporánea; autobiografias.
Abstract. The purpose of this paper is to consider literary education from the point of view of the relationship between literature and life. In these times of crisis in the humanities, we believe it necessary to reclaim the irreplaceable role of literature in the education of children and adolescents. In order to evaluate the transformative power of literature and the vital dimensions of the experience of literary reading in the early stages of identity construction, we explore five autobiographical texts of five Spanish contemporary writers as a source of introspective and retrospective information, in the trend of ethnographic research. In these readers, their exceptional reading experiences add up to an equally outstanding expressive ability to communicate what this intense relationship with literature has represented in their life story, and in their construction as individuals.

Keywords: literature and identity; literary education; contemporary literature; autobiographies.

\footnotetext{
${ }^{\text {I }}$ Para citar este artículo: : Sanjuán Álvarez, Marta y Senís Fernández, Juan (20I7). Literatura e identidad. Experiencias de lectura literaria en la infancia y adolescencia de cinco escritores españoles contemporáneos. Alabe 15. [www.revistaalabe.com] DOI: IO.I5645/Alabe2OI7.I5.2
} 


\section{Introducción}

Después de varios siglos de reflexión sobre el poder de la literatura, Compagnon (2007) se pregunta una vez más para qué sirve la literatura, reducida en muchos casos al simple placer lúdico desde que los enfoques postmodernos le han negado cualquier aplicación social o moral. "La literatura ya no es el modo privilegiado de adquisición de una conciencia histórica, estética y moral, y pensar el mundo y el hombre a través de la literatura ya no es lo más frecuente" (Compagnon, 2007; trad. 2008: 56). Ante esta situación, vuelve a hacerse las preguntas fundamentales que otros muchos pensadores, desde Aristóteles a Jean Paul Sartre o Italo Calvino, ya se habían planteado: ¿Para qué sirve la literatura? ¿Cuál es la pertinencia de la literatura en la vida? ¿En qué consiste su poder? ¿Es la vida más rica para los que leen que para los que no leen?

Podemos concebir estas preguntas desde la perspectiva educativa: ¿Por qué leer literatura en la escuela? ¿Qué sentido tiene la literatura en la formación de los niños y jóvenes? ¿Ayuda la literatura a la construcción de su identidad individual, social y cultural, es decir, les ayuda a ser quienes son, tal como defiende Nietzsche en su Ecce Homo (I888), a partir de la conocida frase de Píndaro “ ¡Llega a ser el que eres!”? Las respuestas dependen de las funciones educativas que cada momento histórico atribuye a la literatura. En la época actual, de claro retroceso de las humanidades, numerosas voces destacadas de la cultura y la educación reivindican la literatura como vía formativa insustituible. Así lo expresaba Calvino (i955. Cit. por Compagnon, 2007; trad. 20o8: 55):

Las cosas que la literatura puede buscar y enseñar son pocas, pero insustituibles: la forma de mirar al prójimo y a sí mismo, [...] de atribuir valor a cosas grandes y a cosas pequeñas, [...] de encontrar las proporciones de la vida, el lugar que en ella ocupa el amor, así como su fuerza y su ritmo, y el lugar que corresponde a la muerte, la forma de pensar en ella o de no pensar en ella, [...] la duración, la piedad, la tristeza, la ironía, el humorismo.

En el contexto educativo español es fácil constatar cómo la educación literaria oscila entre el mero entretenimiento, en aras de que los jóvenes lectores alcancen lo que ambiguamente se conoce como el placer de leer, y su uso instrumental como vehículo para adquirir unos determinados conocimientos o valores fijados antes de la lectura de los textos, incluso antes de su creación, siguiendo la estela de la literatura de tesis o literatura instructiva, de antigua raigambre en lo que a la literatura infantil y juvenil se refiere. Para Compagnon (2007; trad. 2008: 54), "ha llegado el momento de volver a hacer el elogio de la literatura, de protegerla del desprecio, en la escuela y en el mundo”. 


\section{Objetivos y metodología investigadora}

Este trabajo es deudor de algunas líneas de investigación sociológica o etnográfica sobre la lectura (Petit, I999, 2OOI; Peroni, I998; Bahloul, I998; Lahire, 2002; Argüelles, 2003, 2005), que han desplazado el interés desde cuánto se lee hacia cómo se lee y cómo afecta la lectura al lector, con el objetivo de dilucidar "cómo la lectura ayuda a las personas a construirse, a descubrirse, a hacerse un poco más autoras de su vida, sujetos de su destino" (Petit, 200I: 3I). Adoptamos, por ello, una metodología de investigación etnográfica para explorar cinco textos memorialísticos de cinco escritores españoles contemporáneos que relatan y analizan de forma pormenorizada cómo fue su relación temprana, en la infancia y adolescencia, con la literatura, y en qué medida esta ejerció un papel decisivo en la construcción de su personalidad. No pretendemos dar a sus testimonios un valor ejemplarizante, pues se trata, sin duda, de unas vidas singulares y de unas personas dotadas de una sensibilidad excepcional para el lenguaje. Sin embargo, esa intensidad máxima de sus experiencias como lectores puede ayudarnos a apreciar en toda su complejidad el papel que la literatura, y por ende la educación literaria, pueden desempeñar en el desarrollo psíquico de los seres humanos.

Sumándonos a esas voces que alertan sobre la pérdida de la función educativa de la literatura, el objetivo de este trabajo es doble: reivindicar el poder de la literatura en la formación de los seres humanos, e indagar en su capacidad transformadora en los estadios iniciales de la construcción de la identidad, desde la primera infancia hasta el fin de la adolescencia. Creemos contribuir, con ello, a una reflexión encaminada a la superación de unos modelos didácticos de enseñanza de la literatura, todavía muy arraigados en la escuela española, que se alejan de su potencial formativo.

Los autores seleccionados son representativos de un amplio lapso de tiempo, ya que su nacimiento se distribuye a lo largo de cuatro décadas, entre r926 y I959. Las cinco obras se han escrito en la madurez o vejez, con una larga perspectiva sobre la vida vivida y sobre la trayectoria como lector y como escritor:

- José Manuel Caballero Bonald (nacido en r926). Tiempo de guerras perdidas (i995) (obra escrita, por tanto, a los 69 años).

- Josefina Aldecoa (n. en r926). En la distancia (2004) (escrita a los 78 años).

- Antonio Gamoneda (n. en I93i). Un armario lleno de sombra (2009) (escrita a los 78 años).

- Luis Landero (n. en 1948). Elbalcón en invierno (2014) (escrita a los 66 años).

- Fernando Aramburu (n. en i959). Las letras entornadas (20I5) (escrita a los 56 años).

El uso de testimonios autobiográficos para un análisis de las dimensiones vitales de la experiencia de la lectura es habitual en la reciente investigación sociológica o etnográfica sobre la lectura. No se han explorado, sin embargo, las autobiografías o libros de memorias de escritores u otras personas relevantes del mundo de la cultura. No es 
desdeñable el interés investigador que aporta la circunstancia de que en estas memorias la intensidad de las experiencias lectoras vividas se suma a una capacidad expresiva igualmente excepcional para comunicar lo que esa relación intensa con la literatura ha representado en su construcción como sujetos. En el sentido de que la experiencia humana es compartible, puede tener un alto interés el testimonio de cómo se forjaron esas aficiones lectoras o la comprensión de cuáles fueron las transformaciones profundas que la experiencia literaria produjo en estos lectores excepcionales.

\section{Análisis}

Siguiendo el proceso de la investigación etnográfica (Colás y Buendía, r994; García García, 2000), la lectura analítica de los relatos autobiográficos ha dado lugar a la emergencia de categorías que se han agrupado por similitudes en categorías más amplias.

Estos textos ofrecen numerosos aspectos de interés para la educación literaria. Nos hemos ceñido a aquellos más directamente relacionados con el papel que la literatura ha ejercido en la construcción de su identidad. Con el fin de ofrecer al lector una visión de conjunto, a continuación se enumeran los aspectos que se han considerado más relevantes: I) El descubrimiento del lenguaje poético y la magia de las palabras: la dimensión estética de la literatura. La sonoridad de la palabra poética oral; 2) Literatura y vida: la plenitud de la experiencia lectora. La literatura como vida intensificada, vía de conocimiento y superación de un entorno pobre; 3 ) El poeta como modelo vital; 4) La literatura como refugio, como espacio íntimo; 5) Modos de leer y releer.

\section{I. El descubrimiento del lenguaje poético y la magia de las palabras: la di-} mensión estética de la literatura. La sonoridad de la palabra poética oral.

De todas las experiencias tempranas de lectura literaria, quizá una de las que más honda huella han dejado es la del momento preciso en que se descubre la belleza del lenguaje literario y su capacidad para crear mundos propios.

En Antonio Gamoneda el descubrimiento se asocia con el momento de aprendizaje de la lectura a los cinco años, en I936, comenzada la guerra, con un libro de poesía escrito por el padre, ya fallecido. Leer palabras incomprensibles pero creadoras de un ritmo y unas connotaciones más allá del uso denotativo del lenguaje le produjo la revelación del carácter musical de la palabra poética, y la constatación de que esas palabras musicales activaban su pensamiento de un modo visionario, un pensamiento sentiente muy distinto del racional, pero con una gran capacidad de crear realidad. Frente a una comprensión basada en el significado de las palabras, Gamoneda encontró una vía instantánea de acceso al sentido a través de lo connotativo (la música, el ritmo), que no estaba reñida con la ininteligibilidad racional del mensaje (o más bien, del significado): 
El libro, con independencia de la autoridad que le proporcionaba haber sido escrito por mi padre, era un libro de poesía, y yo, de manera primaria y confusa pero intensa, empecé a advertir en él que las palabras comportaban un cuerpo musical, y esta advertencia me hacía sentir (sí; sentir es la palabra), con una emoción hasta entonces desconocida, que las expresiones, casi siempre incomprendidas pero recibidas en su valor musical, activaban en modo visionario mi pensamiento.

Nunca eché de menos las representaciones convencionales, normalizadas y reconocibles. Lo desconocido, presente en aquellas palabras, era, en mí, una realidad que no necesitaba explicaciones [...]. Yo leía: "Si por sus altos vicios y sus bellos pecados / es su alma pagana condenada a bogar / en la sombría barca de los desesperados / ¿quién se podrá salvar?" [...].

Las presencias lingüísticas que no se podían reducir a comunicación llana funcionaban en la elevación del instante; las asociaciones léxicas difícilmente verosímiles [...] eran llevadas al orden de la música y el sentido y éstos sí se me entregaban, inexplicables [...] pero evidentes dentro de una especie de placer hasta entonces desconocida (Gamoneda, 2009: 69-7I).

Ya con I3 o I 4 años, por indicación de un librero, abre al azar la Segunda antolojía poética de Juan Ramón Jiménez y empieza a leer en voz alta. Era la primera vez que se oía leer versos a sí mismo, y esa experiencia le hace advertir, de nuevo, que la poesía es un modo sensible de pensar la realidad, ajeno a la vía intelectiva:

Obedecí y, temblando, leí lo mejor que supe lo siguiente: "El poniente me invade con sus flores / de oro, mientras, largo y lento, canta / el ruiseñor de todos mis amores / ahogándose casi en mi garganta. / / Al ver este oro en el pinar sombrío, / me he acordado de mí tan dulcemente, / que era más dulce el pensamiento mío / que toda la dulzura del poniente. // ¡Oh dulzura de oro, campo verde, / corazón con esquilas, humo en calma! / No hay en la vida nada que recuerde / estos dulces ocasos de mi alma".

Era la primera vez que me oía leer versos a mí mismo. La poesía se hacía en mí más presente y real: sentía el cuerpo musical de las palabras; el ritmo, sobre todo el ritmo, levantaba el valor de la imaginería y de algo más que se desprendía de ésta: un sentido, puede que hasta un significado en esta ocasión. Oírme leer me proporcionaba en modo sensible y conmocionante el pensamiento poético (Gamoneda, 2009: 229).

En el caso de Luis Landero, nacido en una familia campesina, la magia de las palabras se revela en la primera infancia a través de una literatura oral de hondas raíces populares, que le fue transmitida por sus mayores:

Ellos tenían un vasto y viejo repertorio de refranes, canciones, adivinanzas, cuentos, leyendas, versos, fábulas, chistes, anécdotas, decires, habladurías, sucesos famosos y 
verídicos ocurridos desde antiguo en el pueblo o en sus contornos, y uno no se cansaba nunca de escuchar aquellas historias, porque la repetición les daba una pátina que, como a ciertos objetos, las hacía aún más valiosas. Y mientras se contaba, se estaba libre de miedos y amenazas (Landero, 20I4: I7I).

De entre todos los narradores familiares destacaba su abuela Frasca, que "dominaba como nadie el arte de contar" (Landero, 2OI4: I7I), y eso se notaba en cómo manejaba la línea melódica de la voz, las pausas, el movimiento acompasado de las manos, cómo unía las frases, el suspense, la alternancia de episodios lentos y rápidos... "Y así, todo un mundo de fantasía y de palabras malabares vino a poblar mi infancia. Aquellos dichos y relatos fueron los libros que no tuve" (Landero, 20I4: I72-73). Además de hacerle descubrir la sonoridad de las palabras y su capacidad embaucadora, esa literatura oral actuó en su infancia a modo de una mitología primordial que intenta dar respuesta a las grandes preguntas de la vida. El mundo era todo él un misterio, y las palabras que lo nombraban adquirían una cualidad simbólica: "El lobo era cruel, maléfico, y por eso se llamaba lobo, igual que el zorro, por su astucia, se llamaba zorro. La condición y cualidades de las cosas venían pregonadas ya en los nombres" (Landero, 20I4: I76).

A los i6 años escucha un programa de radio en el que un locutor recitaba poesía. La experiencia, al igual que en el caso de Gamoneda, es una experiencia total, multisensorial, emocional. La oralidad otorga a la poesía una musicalidad, una calidez, un cuerpo, que hacen que penetre por una vía distinta a la del intelecto y se cree una realidad intensa, verosímil, inevitable:

Aquellas palabras en el silencio oscuro de la noche brillaban como ascuas celestes, eran pura magia. En aquella voz cada palabra era sagrada. Y también lo eran las pausas, aquel silencio dentro del silencio, como una joya deslumbrante en su estuche. Y cuando acababa el programa, aún duraba un buen rato la magia, y uno cerraba los ojos y se sentía felizmente confundido con el curso de los astros y la secreta armonía del universo (Landero, 2OI4: 82).

Para Fernando Aramburu la vivencia inicial de la experiencia literaria surge también asociada a la literatura oral, pero en el ámbito escolar. A los i4 años, un profesor con buenas dotes de intérprete lee en voz alta unas cuantas páginas de Juan Salvador Gaviota y consigue embaucar a todo un grupo de adolescentes indiferentes:

No le faltaban dotes de intérprete, las suficientes para sacar de la modorra a aquella piña de muchachos embarrados. Recuerdo que cambiaba a menudo el timbre de la voz. Ciertos pasajes los acompañaba con gestos súbitos de entusiasmo, o de melancolía, o de no se sabía muy bien qué. En ocasiones se quedaba unos instantes callado mientras dirigía la mirada misteriosamente hacia algún punto impreciso por encima de nuestras cabezas (Aramburu, 2015: 27-28). 
Simultáneamente, dos compañeros especialmente dotados para la narración oral despiertan su admiración. De uno, narrador de películas, recuerda su especial destreza para graduar la tensión del relato, elegir pormenores sugerentes y acentuar el momento del clímax. El otro, narrador de libros de aventuras, le contagió un entusiasmo que pudo influir en su definitiva conversión en lector asiduo (Aramburu, 20I5: 228-229).

Al final de la adolescencia, ya en plena fiebre creativa como poeta, su aprecio por la palabra poética oral se manifestó más intensamente aún en la costumbre solitaria y extravagante, según sus palabras, de leer en voz alta para sí mismo en la soledad de la habitación de la casa familiar, hasta altas horas de la noche:

Me procuraba un gozo especial leer en voz alta. Obras enteras de teatro de Lope de Vega, Tirso de Molina y de tantos otros, todas en verso, a veces hasta tres y cuatro en una tarde, impostando la voz según a qué personaje correspondiese el parlamento. Y de la misma manera declamaba romances, sonetos y cuantas piezas versificadas cayeran en mis manos, paladeando cada sílaba, deleitándome en las curvas melódicas, adiestrando sin darme cuenta el oído a las sutilezas acústicas de la lengua española. De paso, aprendía de memoria listas de palabras que nunca antes habían sido pronunciadas en mi presencia (Aramburu, 2015: 134).

A Caballero Bonald la revelación del verdadero lenguaje poético, tras anteriores veleidades de carácter romántico como lector y como escritor incipiente, le llegó de manera casual, con I4 o I5 años, al leer la Segunda antolojía poética de Juan Ramón Jiménez. Como a Gamoneda, la lectura temprana de JRJ le descubre un lenguaje poético desconocido, alejado de un lirismo "de falsete", tras el cual "ya nada iba a ser lo mismo":

Fue como si se desmantelaran bruscamente en la memoria todas mis anteriores pertenencias poéticas y descubriera de pronto la maleable utillería de un lenguaje que no era con el que yo me había familiarizado hasta entonces. [...]. Y más tratándose de un joven extraviado por ciertos volubles arrabales de la literatura, acotados todos ellos por un lirismo de falsete. [...]. Es posible que todavía anduviera yo queriendo vagar por los anillos exteriores de la imaginación romántica, es decir, por un suministro poético mezclado de venenos tormentosos muy rápidos de digerir. Pero ya nada iba a ser lo mismo (Caballero Bonald, I995: II7-II8).

Ya hacia los 20 años, la lectura de la poesía de Aleixandre, Salinas y Cernuda le confirma el carácter musical del lenguaje poético, y da lugar a la escritura de poemas "adecuadamente mediatizados por una especie de obstinada propensión a elegir las palabras por su sola cualidad eufónica" (Caballero Bonald, r995: เ96).

También Josefina Aldecoa rememora, entre sus experiencias literarias más tempranas, la escucha asombrada de narraciones orales, literarias o inventadas por sus abue- 
los, así como de los poemas de Machado, Juan Ramón, Lorca o Alberti, recitados con frecuencia en la escuela gracias al buen hacer de un maestro (Aldecoa, 2004: 24).

\subsection{Literatura y vida: la plenitud de la experiencia lectora. La literatura} como vida intensificada, vía de conocimiento y superación de un entorno pobre.

Las experiencias de lectura pueden llegar a ser tan intensas que se convierten en una vida sustitutiva de la real, mucho más pobre. Se desarrollan, así, dos procesos que conectan literatura y vida: el vivir otras vidas paralelas a través de la literatura, o bien el vivir la vida real bajo la óptica de la literatura, como Don Quijote.

En el caso de Aramburu, el recuerdo de determinadas experiencias lectoras de adolescencia y juventud es tan vivo que esos hitos lectores se convierten en experiencias emocionales e intelectuales más significativas que los propios hitos vitales:

No he participado en batallas, ni he navegado por mares ignotos, nunca pisé la Luna. En cambio, me han ocurrido grandes lecturas. Los días y noches en que leí a Miguel de Cervantes, a Fiódor Dostoievski, a Vicente Aleixandre o a Franz Kafka, entre otros, fueron para mí, tanto por sus efectos como por la intensidad emocional e intelectual de la experiencia, eso que podemos llamar, sin caer en la tentación de ponernos estupendos, momentos estelares en la vida de un individuo común (Aramburu, 20I5: I55).

La literatura supuso la emancipación de una realidad triste a la que se oponía la realidad virtual que se creaba mediante la estética del arte. Esas lecturas tempranas le permitían trasladarse a otras formas de vida superiores, sobre todo estéticamente:

Conforme iba adquiriendo conocimientos y leía libros, desarrollé una especie de discrepancia estética frente a mi entorno social. Puede decirse que mi primera emigración la llevé a cabo mentalmente y que estaba determinada por el gusto. En cierto sentido, vivía alejado de las personas que me rodeaban, como separado de ellas por una membrana transparente (Aramburu, 20I5: 257).

Muy pronto Aramburu adquirió conciencia de que la cultura y la literatura eran la única vía para el ascenso social, para escapar de un entorno con el que no se conformaba:

Con los medios escasos de que disponíamos aún me cuesta creer que años más tarde me fuera dado esquivar la suerte a que, por mi nacimiento humilde, estaba probablemente destinado. A mí me sacaron del pozo los libros y el estudio del idioma. [...] en cualquier modelo de sociedad el hombre sin cultura se lleva siempre la peor parte, si es que se lleva algo (Aramburu, 2OI5: I7). 
Esa conciencia promovió un plan sistemático de lecturas para adquirir el "estilo alto" del idioma, pero no solo como acceso a una estética del lenguaje, sino también a una ética, una vía de conocimiento y una manera nueva de nombrar el mundo con conceptos inusitados. Un hito especial fue la lectura de Vicente Aleixandre:

Recluido en mi habitación, yo leía con afán de aprender y disfrutar de sus poemas caudalosos, de sonoridad exuberante, de una grandeza expresiva imposible en mi medio social; poemas salpicados de tantas cosas que nos faltaban; de maravillas conceptuales, por ejemplo, y de combinaciones novedosas de las palabras, y comprendía que lo que aquel poeta me daba [...] era no sólo un conjunto de textos valiosos por su profundidad y su hechura extraordinaria, sino una opción para mí liberadora, una escala con la cual salir de aquel pozo de los privados de la palabra en que yo me hallaba atrapado por razón de mi modesto origen (Aramburu, 20I5: II9).

También Caballero Bonald considera que sus lecturas literarias de adolescencia le sirvieron para superar y dignificar la realidad ramplona y gris del Jerez inmediatamente posterior a la guerra. La literatura abría, además, una vía de libertad, de evasión. En compañía de un primo también lector, la literatura se transformó en una forma de vida provocadora que pretendía escandalizar a la sociedad pacata. La literatura les ofrecía unas claves, un proyecto de vida distinto del que la triste realidad les permitía:

Tal vez de un modo instintivo, necesitábamos neutralizar, no importa que dando palos de ciego, la ramplonería, el mezquino estatismo social y cultural de aquel Jerez de los años 40. Éramos en paridad los primeros adolescentes de la posguerra y todavía no nos habíamos enterado de nada, ni siquiera de que estábamos usando una especie de variante con minúsculas de la libertad frente a la general privación de libertades. Cumplimos pues a rajatabla con nuestro cupo juvenil de intemperancias y desobediencias, si bien ninguna de ellas tenía el más remoto parecido con algún airado inconformismo de carácter ideológico (Caballero Bonald, I995: Io9).

La relación entre poesía y vida es estrecha a lo largo de toda la autobiografía de Antonio Gamoneda. Como en el caso de Caballero Bonald y de Aramburu, la poesía le abre muy pronto una vía para liberarse de un entorno pobre y opresor, pero simultáneamente se convierte en creadora de un saber, de una experiencia que supera a la real. En su caso, la vida marcada por la literatura tiene un hito destacado: aprender a leer con el libro de poemas escrito por su padre le supuso no solo la revelación de la poesía como forma de pensamiento, sino una relación real e intensa con el padre ausente:

En mi vida de adulto, no he encontrado nada más decisivo en relación con la palabra poética. Aquel niño deslumbrado me dejó claro para siempre que el lenguaje de la poesía se 
sabe y entiende (utilizo estos términos y no digo, por ejemplo, "se comprende", porque estoy seriamente prendido y convicto del "no saber sabiendo" y del "entender no entendiendo” de Juan de Yepes), que el lenguaje de la poesía se sabe y entiende, decía, en el exterior del lenguaje conversacional e informativo. Su realidad (no confundir, por favor, realidad y realismo) es de otra especie. Aún quiero decir algo más: considero imposible que, con la muerte por medio, pueda darse una relación más real entre un padre y un hijo que la que aconteció en mi infancia (Gamoneda, 2009: 72-73).

Landero comparte con todos ellos la experiencia de la literatura como una vida alternativa a la sórdida realidad de la España de la época (finales de los 5 o y comienzo de los 6o): “El mundo objetivo palidecía y se desvanecía ante la vívida realidad de los libros y de la escritura" (2OI4: I3I). El primer libro adquirido con su dinero fue Las mil mejores poesías de la lengua castellana. Ese libro le procuró una relación plena, amatoria, la sensación de que "lo contenía todo". Su lectura constituyó una experiencia intelectual, estética y emocional, detonante para el comienzo de su escritura poética:

Durante mucho tiempo fui feliz con aquel libro, feliz acaso como nunca en la vida. Fue un verdadero idilio, el más hermoso que uno se pueda imaginar. Aquel libro era mi amada y yo era su amado, el libro y yo, los dos juntos, inseparables, viviendo no importa cómo ni dónde, y condenados a ser dichosos para siempre. Porque a mí me parecía que con aquel libro era bastante para toda la vida, y no hacían falta ya más libros, como tampoco los enamorados de verdad necesitan de ningún otro amor. Toda la literatura, toda la sabiduría, toda la belleza del mundo, estaban contenidas en aquellas setecientas páginas. Y un día escribí mi primer poema, temeroso quizá de estar profanando algo (Landero, 2OI4: 85-86).

Para Josefina Aldecoa, la literatura entró sin enfrentarse a la vida real -plena de afecto y estímulos intelectuales-, sino más bien como una manera de enriquecerla. De la experiencia lectora en la infancia Aldecoa extrae tres dimensiones principales relativas a lo que supuso la literatura para la construcción de su personalidad: la dimensión intelectual (dar forma y sentido a lo que se vive y abrir a la comprensión de lo desconocido), la dimensión emocional (desarrollar la sensibilidad, el sentimiento) y la dimensión ética (acercamiento solidario a otros seres humanos):

El descubrimiento del juego creativo del pensamiento, la asociación de ideas, la fascinante explicación de misterios en apariencia inexplicables, me abrieron, desde la infancia, caminos de una riqueza incomparable a cualquier otra. Ese comienzo temprano en la experiencia del trabajo mental organizado, bien dirigido y bien estructurado, se lo debo a mi madre, una espléndida maestra. [...]. El mundo de los libros, la pasión por la lectura precozmente despertada, suponen un estímulo decisivo que acelera la constante evolu- 
ción, el creciente interés por lo desconocido, el cauce para dar forma y sentido no sólo a la función intelectual sino también a la sensibilidad y a la capacidad de acercamiento solidario hacia el resto de los seres humanos (Aldecoa, 2004: $3^{\mathrm{I}-32}$ ).

Casi al final de sus memorias, cuando hace balance de lo que han supuesto en su vida la lectura y la escritura, insiste en el papel central que la literatura ha desempeñado como vía para llegar al conocimiento de sí misma y de los demás:

Creo que, en el fondo, el impulso que nos lleva a escribir es el mismo que el impulso que nos lleva a leer. En el primer caso, escribir, saber más de nosotros mismos y comunicarlo a los demás. En el segundo, leer, saber más de otros seres humanos que un día, quizá cien años antes, nos contaron en sus libros lo que ellos sentían y pensaban y cómo lo vivían (Aldecoa, 2004: 198).

\section{3·3. El poeta como modelo vital.}

Dando un paso más en el camino hacia la literaturización de la vida, puede llegar a producirse un deseo de vivir como poeta, de adoptar una forma de vida literaria.

En el Caballero Bonald adolescente, tras la etapa de poeta iconoclasta, la lectura de la poesía de Espronceda, pero sobre todo de su biografía asombrosa, provoca un deseo intenso de emularlo, de vivir según los parámetros de poeta romántico:

La desesperación lírico-dramática de Espronceda, como trasunto fiel de mi fingida desesperación, constituyó el primer imperioso vínculo operativo. Me llevó mi trabajo encontrar el método más idóneo para que esas disipaciones me proporcionaran un buen motivo de inspiración poética. Probé muchas nocturnidades y alguna que otra alevosía, todo ello con la debida premeditación y de acuerdo con mis precarias disponibilidades económicas. Fue una temporada inolvidable y ya me veía admitido en el Parnaso en razón de los muchos méritos contraídos. [...]. Mientras practiqué ese voluble aprendizaje, escribí un buen número de poesías, todas ellas del género melodramático, que el tiempo ha tenido la deferencia de extraviar (Caballero Bonald, I995: IOz).

La figura de lánguido escritor de versos de enamorado incomprendido es la que adopta Landero como modelo de vida y escritura hacia el final de su adolescencia:

[...] había dado un estirón y ahora era esbelto y atractivo, y el ser y saberme poeta me daba un aire solitario de extranjero sin patria que era un motivo más de seducción. Ya había tenido dos novias y ahora andaba por la tercera, a la que le escribía poemas tristes de amor, aunque quizá de quien tú estabas enamorado de verdad era de la poesía más que de las novias, y las novias eran solo un pretexto para componer versos (Landero, 2OI4: I37). 
En el caso de Aramburu, ser poeta se convierte en un proyecto de vida que se desarrolla a contracorriente del entorno, como una tarea casi clandestina, e incluye la lectura compulsiva, las lecturas declamatorias, el aprendizaje consciente del "estilo alto" del idioma y también los primeros ejercicios de escritura: "Quizá lo extraño, ahora que lo pienso, fuera que a edad tan corta supiese con certeza la dirección que deseaba imponerle a mi vida. Varias décadas después sigo comprometido en el proyecto de un adolescente" (Aramburu, 20I5: 134). En sus años juveniles, la pertenencia a un grupo poético surrealista (el grupo CLOC) le llevó a adoptar públicamente el personaje del poeta provocador, rompedor de clichés estéticos más que ideológicos. Esa presencia pública fue acompañada muy pronto del reconocimiento social y familiar.

Gamoneda, por su parte, no cree que el ser poeta constituya un modelo de vida adoptado de modo voluntario. El pensamiento poético es, para él, una forma de existir que no suplanta su realidad biográfica, sino que es parte indisoluble de ella (2009: 236).

\section{3•4. La literatura como refugio, como espacio íntimo.}

Las experiencias de lectura de la infancia y la adolescencia, a veces las más intensas desde el punto de vista emocional, van asociadas con frecuencia a unos tiempos y unos espacios íntimos que acentúan la percepción de la lectura como refugio.

Josefina Aldecoa ambienta principalmente sus lecturas de infancia en la casa rural de sus abuelos maternos. La buhardilla de la casa se transforma en refugio simbólico:

Las manzanas se guardaban en la bohardilla, extendidas en el suelo. [...]. En aquel espacio cerrado y silencioso descubrí el gozo de la soledad, la soledad como el mayor de los lujos. Tumbada sobre una manta de colores en el cuarto de las manzanas leía cuentos y novelas de aventuras y, al levantar los ojos del libro, contemplaba a través de las ventanas los árboles del río, abajo, y el cielo claro y duro, arriba. [...]. Después regresaba a la lectura. La gran huida hacia otros mundos. [...]. Aquella casa de mis abuelos fue mi primer refugio sobre la Tierra (Aldecoa, 2004: I7-2O).

También para Landero el escenario preferido para sus lecturas de infancia es el desván de la casa familiar de labranza, un espacio lleno de aromas y sensaciones que favorecían la ensoñación. Con la palabra "cubil” nombra tanto el espacio físico en el que refugiarse para leer en soledad como ese espacio secreto e íntimo que se crea al leer:

En la penumbra de los desvanes se guardaba el grano, y extendidos sobre el suelo se conservaban calabazas, melones, camuesas, membrillos, de modo que aquellos lugares, con sus buenos aromas, estaban hechos como a propósito para acoger la soledad de un niño. Allí me sentía seguro, porque estaba en casa pero a la vez estaba a salvo de la familia y de los deberes familiares. Doblemente seguro pues. La ensoñación de un lugar secreto, de un refugio, siempre me ha subyugado. Un día deberías escribir algo sobre el 
refugio como motivo literario, Elogio del cubil, podría titularse, porque los mejores y más seguros escondrijos los has encontrado siempre en los libros. [...] el lector, como los personajes en el seguro de una cueva o de un cerco de estacas, encuentra su refugio en el libro. Esconderte en un libro, en el cálido cubil de las palabras, eso es lo que has hecho tantas veces, como de niño en los desvanes (Landero, 20I4: 222-223).

Para el Caballero Bonald adolescente, la poesía se convierte en el único refugio para una pasión amorosa imposible:

La cosa duró más de lo razonable y por primera vez sentí que una pasión de la clase de las avasalladoras me instaba a buscar un lenitivo que únicamente podía encontrar en los refugios ilusorios de la poesía lírica (Caballero Bonald, I995: II5).

\subsection{Modos de leer y releer.}

Si algo caracteriza la manera de leer de estos lectores apasionados es la indisoluble conexión que son capaces de establecer entre literatura y vida, en un doble sentido:

- El lector aporta a la lectura todo lo que es, su experiencia vital y lectora, sus herramientas cognitivas y emocionales, tanto conscientes como inconscientes.

- El texto literario afecta e incluso transforma al lector, la lectura se convierte en una experiencia similar a la experiencia vital.

Buen ejemplo de la primera faceta, la que se refiere a un modo de leer e interpretar el texto desde las experiencias vitales, lo constituye el gusto que declara Landero por los detalles realistas que dan algunos escritores, especialmente cuando tratan cuestiones de dinero o comida, que forman parte de sus obsesiones desde pequeño. Sin duda esos detalles acentúan la verosimilitud de la ficción y ponen en marcha un mecanismo de identificación entre las experiencias del lector y las situaciones que viven los personajes:

Me gusta que me hablen de cifras exactas, como hacen por ejemplo Balzac o Dickens, lo que gana cada cual, lo que cuestan las cosas, el montante de una herencia, de un robo, de un tesoro. Del dinero (del chico y del grande, pero sobre todo del chico) quiero saberlo todo.

También me gusta saber con exactitud lo que come la gente. Valoro mucho en el Lazarillo las uvas, el vino, la longaniza, el nabo, los bodigos, la cabeza de carnero, las uñas de vaca, los mendrugos de pan. Esos detalles son oro puro para mí. Sin ellos, además, el Lazarillo sería otro tipo de libro, no el que es. En el Quijote se deja muy claro desde el principio qué es lo que come nuestro héroe [...]. Galdós cuenta no sé dónde que aquel día había en el mercado una merluza de buen ver, a no recuerdo cuántos reales el kilo. Me sé de memoria los menús de Robinson Crusoe, las fatigas del Buscón, y casi todas las hambres y los festines de los grandes carpantas y tragaldabas de la literatura universal. Deberías escribir un libro sobre el dinero chico y sus milagros cotidianos, comenzando por aquel real que te daban para que te durase toda la tarde de domingo (Landero, 20I4: 227-228). 
Del segundo aspecto, cómo la lectura verdadera deja una huella profunda y transforma al lector, son numerosos los ejemplos que ofrecen estos textos. Ya hemos señalado cómo en ocasiones la lectura llega a convertirse en una experiencia vital sustitutiva de la real. Los procesos de lectura o modos de leer asociados a esas lecturas intensas varían en función de la edad o circunstancias vitales que rodean el acto de leer. Existe una manera de leer emocional, impulsiva, abierta a la sorpresa, al asombro. Es muy propia de la infancia esa lectura sin filtros intelectuales, una lectura gozosa que consiste en dejarse llevar, en un viaje a lo desconocido. Así, frente a otras experiencias de la infancia que han palidecido con el paso de los años, el Landero adulto todavía descubre en su yo más profundo la emoción que le proporcionaban los viajes de los grandes relatos míticos, que transformaban simultáneamente al héroe y al lector:

$\mathrm{Al}$ cabo de los años, mis mejores viajes, los que recuerdo con más emoción, y los más llenos de aventuras y experiencias, son los que hacía de niño entre el pueblo y el campo. Viajes aquellos comparables en mi corazón a las andanzas míticas de la antigüedad, las de Simbad, las de Odiseo, las de Moisés y su pueblo elegido, las de Marco Polo, las de los príncipes y jóvenes animosos que iban en busca del dragón o el tesoro, o Ahab y la ballena, o los conquistadores y descubridores, o los viajes científicos de Humboldt o de Darwin... Como lector sigo conservando el mismo incansable y gozoso espíritu viajero que alguna vez tuve en la infancia (Landero, 2OI4: 152).

También a Fernando Aramburu la literatura le permitía viajar virtualmente para explorar otras formas de vida más excitantes. Cuando, con ocasión de un premio literario, tiene la ocasión de disfrutar de unos días de estancia en París, la realidad se impregna gozosamente de las experiencias literarias vividas. La literatura se convierte en una lente emocional que agranda la vida real y permite percibirla de un modo "extrasensorial":

En la calle me gustaba todo de una manera jubilosa: los puentes, los letreros, las fachadas. A la memoria me vinieron, claro está, los escritores de mi lengua que alguna vez se establecieron en París. César Vallejo, Julio Cortázar (que aún vivía), tantos otros cuya invisible presencia me parecía percibir entre los detalles del mobiliario urbano y en no sé qué propiedades y vibraciones del aire (Aramburu, 20I5: 258-259).

A veces la experiencia lectora funde lo emocional y lo intelectual. Esto sucede cuando la literatura se convierte en una vía de conocimiento que ilumina la realidad a la vez que conmueve. Se puede comprender la realidad de un modo que no existiría fuera de la recreación literaria. Más aún: la literatura es capaz de crear realidad. La vida se acomoda a la literatura, la realidad imita al arte. Esa literaturización de la vida es evocada en numerosas ocasiones por estos lectores apasionados, que desde la infancia han aprendido a mirar la vida a través de la lente de la literatura, aunque ese poder de la literatura para 
crear una nueva realidad no siempre produce los efectos deseados ni de modo duradero. Así, Landero evoca cómo sus primeras lecturas literarias sobre la belleza del campo le hicieron percibir de una manera nueva el paisaje y las formas de vida conocidas desde siempre, aunque ahora, en su edad madura, su lente es bien distinta:

Recuerdo mi estupor y mi alegría cuando leí en los libros de texto los primeros fragmentos literarios donde se describía la belleza del campo, y las ganas locas que sentí de ver a mis padres y a mis abuelos y a mis tíos y a mis primos mayores para contarles lo bonita que era la naturaleza, sus muchos colores y tonalidades, el horizonte, el canto de los pájaros al amanecer, la paz y el silencio, el rumor del arroyo. Ahora sé que se hubieran reído de mí, del mismo modo que ahora, cuando recuerdo los campos de mi niñez, por encima de la belleza, se me revela ante todo un paisaje hecho de historia; es decir, de tiempo y de dolor (Landero, 20I4: I82-I83).

En sus años de juventud, en una fiesta en Moscú en la que por casualidad se encontraba también Sara Montiel, se vio de pronto "transmutado" en Julien Sorel, protagonista de Rojo y negro, cobró coraje y se acercó a ella para sacarla a bailar. El desdén recibido como respuesta se transformó en su interior en una versión fabulosa del suceso mucho más "justa” y acorde con las leyes de la ficción literaria: Sofía Loren, también "presente" en la fiesta, le concedía un gentil baile (Landero, 2OI4: I94-I95).

Caballero Bonald, por su parte, observa las Rías Bajas gallegas a través de la lente brumosa de Rosalía de Castro, y del mismo modo colma de intensidad melancólica una relación amorosa con una muchacha gallega, hasta que se agota el "literario fingimiento" (Caballero Bonald, I995: I82-I83).

Las emociones asociadas a estas lecturas tempranas de la infancia y la adolescencia son muy variadas pero siempre intensas: asombro, evasión, miedo, risa, gozo de leer lo prohibido... Tanto Landero (2OI4: II5) como Aramburu (2OI5: 73) se refieren a la relectura como una experiencia de reencuentro con el yo emocional de la infancia.

A veces la literatura produce un auténtico trastorno, una conmoción. Gamoneda recuerda cómo afectó a su sensibilidad, hasta el punto de crearle terrores nocturnos durante una buena temporada, el escuchar una cancioncilla popular que recreaba el truculento martirio de Santa Catalina (2009: I2O). La transformación puede llegar a tener incluso un efecto físico, afectar al temperamento. Aramburu considera que su afición a la lectura y posterior avidez de lector acabó con el niño movido y travieso y dio paso a otro modo de ser: "Leyendo libros me fui habituando a la serenidad y el recogimiento" (Aramburu, 2OI5: 2I).

Junto a estas maneras de leer desordenadas y de carácter básicamente emocional, se evocan también otras lecturas más canónicas y otros modos de leer más reflexivos e intelectuales, casi siempre asociados a la escuela, pero también a algún mediador familiar que dirige las lecturas o incluso a algún plan de lecturas personal y autoimpuesto, con 
una finalidad autodidacta que va más allá del mero gozo de leer. Aldecoa alude al trabajo intelectual sistemático, guiado por su madre, que incluía buenas dosis de esfuerzo, concentración y entrega, pero es recordado como fuente de "los placeres más apasionantes, las compensaciones más completas" de su vida (Aldecoa, 2004: 3I).

\section{Discusión de resultados y conclusiones}

¿Qué podemos aprender de estos escritores, lectores apasionados de literatura? I) El análisis ha confirmado que la experiencia lectora puede llegar a ser más intensa y vívida que la experiencia real, y que incluso puede crear realidad. La palabra experiencia, indica Larrosa (2003), viene del latín experiri, probar, de modo que la experiencia es un itinerario singular de pruebas que conducen hacia uno mismo. La potencia de la imaginación para crear realidad a partir de la ficción literaria es uno de los componentes fundamentales que destaca Larrosa de la experiencia de la lectura. Para Sánchez Corral (2003) los textos literarios exigen transgredir los códigos de la realidad convencional para inventar o reinventar la realidad por medio de la ficción estética, lo cual no supone un escapismo de la realidad, sino otra vía de percepción y conocimiento.

2) Los textos analizados muestran, además, que no hay lectores genéricos o interpretaciones genéricas, sino innumerables relaciones entre lectores y textos, como señala Rosenblatt (1938; reed. ampliada 2002). Para la educación literaria resulta fundamental el concepto de respuesta lectora, tal como muestra la investigación realizada con niños y jóvenes escolares (Sarland, I99I; Sipe, 2002; Cuesta, 2006; Calvo, 20I5). Las distintas posibilidades de interacción entre un texto y un lector infantil o juvenil parecen determinadas en gran medida por sus esquemas sociales y culturales, porque los lectores entienden los textos desde sus experiencias vitales. La profundidad y originalidad de las respuestas lectoras de estos lectores excepcionales revelan una gran diversidad de conocimientos estéticos, experiencias e ideas previas de los que partían en sus etapas de formación para construir el sentido de los textos, unos modos de leer personales pero no por ello erróneos o incompatibles con los saberes legitimados por los lectores autorizados. Desde la perspectiva de las experiencias lectoras, tan diversas y personales, podemos plantearnos, como Salinas (I948), qué es leer bien. Salinas se opone tanto a los protocolos de lectura que imponen un orden rígido en los procesos lectores como a una visión intelectualista de la lectura. Como muestran los testimonios analizados, los procesos intelectivos y emocionales de la lectura son simultáneos. También para Lewis (I96I), cualquiera que sea el valor de la obra literaria este solo se hace realidad cuando hay buenos lectores, y esa buena lectura incluye, necesariamente, la respuesta personal. La tendencia creciente a ver los libros a través de las lentes de otros libros, advertía Lewis, hace difícil esa respuesta personal. Nuestra tradición escolar de enseñanza literaria no favorece, en general, la respuesta personal, en gran medida emocional, de los alumnoslectores, la cual debería ser considerada como un componente intrínseco del proceso 
lector (Sanjuán, 20I3).

3) Por otra parte, la intensidad de las experiencias de lectura literaria parece muy sujeta al azar del encuentro entre el libro adecuado para el lector adecuado en el momento adecuado: difícil conjunción como meta para la tarea escolar. Es casi imposible prever cuándo y cómo se pueden producir esos encuentros felices que provocan la revelación de lo literario. Aun concediendo al azar su parte de protagonismo, de las memorias analizadas podemos extraer dos claves: favorecer el acceso de los niños y adolescentes a una gran diversidad de libros (en cuanto a temas, géneros, estilos, formatos, etc.) puede facilitar el encuentro; después, habrá que procurar que las maneras de leer propicien la vinculación de los textos con las experiencias vitales de los lectores.

4) Si nos planteamos qué es el placer de leer, advertimos cómo estos grandes lectores ejemplifican la idea del placer que supone leer libros difíciles para todo aquel que busque algo más que simple diversión. En lo que atañe a la educación literaria, por tanto, tampoco se debería equiparar el placer de leer con el mero entretenimiento. Las dimensiones éticas e intelectuales de la literatura deberían ser inseparables de las estéticas y emocionales, si queremos recuperar todo su potencial formativo.

5) ¿Cuál es el poder de la literatura, en definitiva? ¿Qué función puede desempeñar la ficción literaria en el desarrollo psíquico del individuo, especialmente en las etapas de formación? La imaginación que desencadena la ficción literaria supuso para estos escritores un medio de ampliar la experiencia individual más allá de sus limitaciones objetivas, ya que les permitió asimilar experiencias ajenas, como destaca Vygotsky (I930). Para Bruner (I986), el proceso de crecimiento de la conciencia a través de la ficción literaria puede deberse a que la literatura facilita la construcción de mundos mentales verosímiles sobre la condición humana, una modalidad narrativa del pensamiento que antecede a la modalidad lógico-científica. Hemos apreciado cómo estos escritores, desde niños, desarrollaban toda una actividad psíquica al leer, se apropiaban de lo leído y deslizaban entre las líneas del texto sus deseos y fantasías. Quizá en la literatura encontraron, puesto en palabras, lo que vivían de manera difusa (Bettelheim, I976). El psicoanálisis analiza en profundidad los procesos morales, intelectuales y emocionales, conscientes e inconscientes, que la literatura desencadena en los receptores.

El análisis realizado nos permite afirmar, en síntesis, que la lectura literaria es una práctica liberadora, ayuda a dar sentido a la vida, es vía de conocimiento del mundo y de construcción de la propia identidad, a través de procesos tanto conscientes como inconscientes. Todo ello mediante un uso del lenguaje que busca conmover al lector, hacerle entender a través de un pensamiento sentiente. De ahí la necesidad de recuperar el poder educativo de la literatura en la formación de los niños y jóvenes. 


\section{Referencias bibliográficas}

- Argüelles, J. D. (2003). ¿Quéleen los que no leen? México: Paidós.

-Argüelles, J. D. (2005). Historias de lecturas y de lectores. México: Paidós.

- Bahloul, J. (I998; trad. 2002). Lecturas precarias. México: FCE.

- Bettelheim, B. (1976; trad. 1977). Psicoanálisis de los cuentos de hadas. Barcelona: Crítica.

- Bruner, J. (ı986; trad. I988). Realidad mental y mundos posibles. Barcelona: Gedisa.

- Calvo, V. (20I5). La lectura literaria en los procesos de acogida e inclusión de adolescentes inmigrantes. Zaragoza: Prensas de la Universidad de Zaragoza.

- Colás, P. y L. Buendía (1994). Investigación educativa. Sevilla: Alfar.

- Compagnon, A. (2007; trad. 2008). ¿Para qué sirve la literatura? Barcelona: Acantilado.

- Cuesta, C. (2006). Discutir sentidos. Buenos Aires: Libros del Zorzal.

- García García, J. L. (200o). Informar y narrar: el análisis de los discursos en las investigaciones de campo. Revista de Antropología Social, 9, 75-IO4.

- Lahire, B. (2002; trad. 2004). Sociología de la lectura. Barcelona: Gedisa.

- Larrosa, J. (2003). La experiencia de la lectura. México: FCE.

- Lewis, C. S. (196I; trad. 200o). La experiencia de leer. Barcelona: Alba Editorial.

- Peroni, M. (1998; trad. 2003). Historias de lectura. México: FCE.

- Petit, M. (1999). Nuevos acercamientos a los jóvenes y la lectura. México: FCE.

- Petit, M. (200I). Lecturas: del espacio íntimo al espacio público. México: FCE.

- Rosenblatt, L. (I938; edic. ampliada y trad. 2002). La literatura como exploración. México: FCE.

- Salinas, P. (1948; reed. 2002). El defensor. Madrid: Alianza. 
- Sánchez Corral, L. (2003). Didáctica de la literatura: relaciones entre el discurso y el sujeto. En A. Mendoza (coord.). Didáctica de la lengua y la literatura para Primaria (pp. 29I3I7). Madrid: Pearson.

- Sanjuán, M. (20I3). La dimensión emocional en la educación literaria. Zaragoza: Prensas de la Universidad de Zaragoza.

- Sarland, C. (I99ז; trad. 2003). La lectura en losjóvenes. México: FCE.

- Sipe, L. R. (2002). Talking back and taking over: Young children's expressive engagement during storybook read-alouds. The Reading Teacher, 55/5, 476-483.

- Vygotsky, L. S. (I930; trad. 1982). La imaginación y el arte en la infancia. Madrid: Akal.

\section{Corpus de obras analizadas}

- Aldecoa, J. (2004). En la distancia. Madrid: Alfaguara.

- Aramburu, F. (20I5). Las letras entornadas. Barcelona: Tusquets.

- Caballero Bonald, J. M. (I995). Tiempo de guerras perdidas. Barcelona: Anagrama.

- Gamoneda, A. (2009). Un armario lleno de sombra. Barcelona: Círculo de Lectores.

- Landero, L. (20I4). Elbalcón en invierno. Barcelona: Tusquets. 